\title{
What you need to know about cancer drugs
}

\author{
Fiona Godlee editor in chief
}

The BMJ

Last year, writing in The BMJ, Peter Wise told us that cytotoxic chemotherapy had done little to extend life of people with cancer (doi:10.1136/bmj.i5792). Most of the added years were due to earlier diagnosis and treatment, he said, and he called for higher bars to drug approval, accurate and impartial information for patients, and rejigging of our clinical priorities.

This week brings further news in a similar vein. A systematic study of cancer drugs approved by the European Medicines Agency in recent years finds that most had no supporting evidence of better survival or quality of life (doi:10.1136/bmj. j4530). The few drugs with evidence of benefit achieved only marginal gains. As Deborah Cohen explains in her accompanying Feature (doi:10.1136/bmj.j4543), the researchers also found that decisions about which drugs to approve were often based on uncontrolled studies or surrogate endpoints, without firm requirements for postmarketing evaluation. Drugs once rejected by EMA may be approved later- "No one wants to say no to a cancer drug," said one EMA adviser Cohen spoke to-and are kept out of the market only through the vigilance of bodies such as the UK's National Institute for Health and Care Excellence. As Vinay Prasad says in a linked editorial (doi:10.1136/bmj.j4528), the result is increased cost, unrealised hopes, and harm to patients, and because the regulators are lax it's payers who have had to wield the stick.

Jessica Pace and colleagues understand the desire for speed and funding of new treatments (doi:10.1136/bmj.j4494), given that this is underpinned by compassion and concerns about inequity. But media rhetoric and hype are fuelling what they call the "access imperative": the growing sense that drugs for severe or life threatening illness shouldn't have to wait for regulatory approval.

Combating these forces will be hard. Researchers will always want to promote their work, manufacturers their products, and the media emotive stories, and desperate patients may want to try even unproved remedies. But Pace and colleagues caution against lowering standards of evidence or disregarding usual cost effectiveness thresholds. Drugs that are rushed through the regulatory process are more likely to gather safety warnings at a later date (doi:10.1136/bmj.j3837). Rather, we should hold research institutions accountable for claims made in their press releases, enforce rules against off-label marketing of drugs, and set media standards for reporting positive and negative outcomes of trials.

Pace and colleagues also suggest increased support for publicly funded clinical trials and drug pricing that is linked to demonstrable evidence of effectiveness. And Prasad adds, I am glad to say, a call for sharing of patient level data.

But while approval and oversight of cancer drugs are so lacking, the cycle of poor evidence generation, wasted resources, and disappointment to patients will continue. 